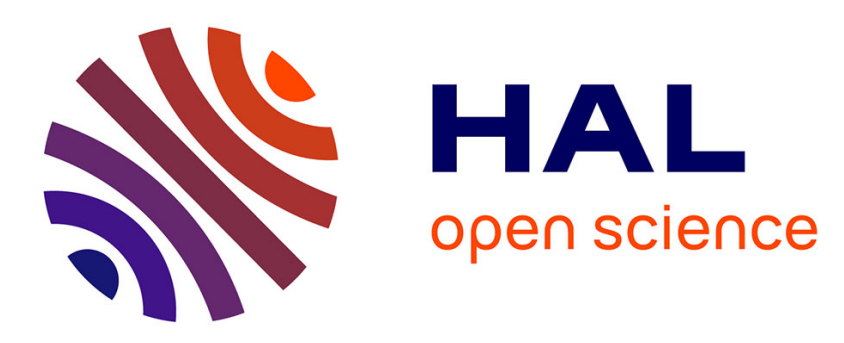

\title{
Simulating Spectral Heterogeneity In Tropical Forest Canopy Reflectance With 3d Radiative Transfer Modeling
}

Dav Ebengo Mwampongo, Florian de Boissieu, Claudia Lavalley, Grégoire Vincent, Christiane Weber, Jean-Baptiste Feret

\section{To cite this version:}

Dav Ebengo Mwampongo, Florian de Boissieu, Claudia Lavalley, Grégoire Vincent, Christiane Weber, et al.. Simulating Spectral Heterogeneity In Tropical Forest Canopy Reflectance With 3d Radiative Transfer Modeling. WHISPERS, Workshop on Hyperspectral Image and Signal Processing: Evolution in Remote Sensing, Sep 2019, Amsterdam, Netherlands. hal-02445433

\section{HAL Id: hal-02445433 \\ https://hal.umontpellier.fr/hal-02445433}

Submitted on 20 Jan 2020

HAL is a multi-disciplinary open access archive for the deposit and dissemination of scientific research documents, whether they are published or not. The documents may come from teaching and research institutions in France or abroad, or from public or private research centers.
L'archive ouverte pluridisciplinaire HAL, est destinée au dépôt et à la diffusion de documents scientifiques de niveau recherche, publiés ou non, émanant des établissements d'enseignement et de recherche français ou étrangers, des laboratoires publics ou privés. 


\section{Simulating spectral heterogeneity in tropical forest canopy reflectance with 3D radiative transfer modeling}

Dav M. Ebengo (1), Florian de Boissieu (1), Claudia Lavalley (1), Grégoire Vincent (2), Christiane Weber (1) and Jean-Baptiste Féret (1)

(1) TETIS, Irstea, AgroParisTech, CIRAD, CNRS, Université de Montpellier, Montpellier, France; dav.ebengo@teledetection.fr

(2) AMAP, IRD, CIRAD, INRA, CNRS, Université Montpellier, Montpellier, Montpellier, France Introduction

- Biodiversity monitoring needed to mitigate the erosion of biodiversity $\rightarrow$ Remote sensing can provide information for such task

- Spectral Variation Hypothesis (Palmer et al. 2002): potential for biodiversity mapping in tropical forests using spectral info (Féret \& Asner 2014)

- Operational applications need validation of experimental results and identification of potential and limitations of existing and future satellite missions

- Physical modeling allows better understanding of how to link remote sensing data with vegetation properties

\section{How to represent complex concept such as biodiversity with 3D physical modeling?}

\section{Objective}

- Test two representations aiming at simulating spectral heterogeneity by taking into account horizontal variability in leaf optical properties (LOPs) :

- ITC approach : LOPs identical for all pixels within an Individual Tree Crown (ITC)

- Pixel approach: LOPs vary among pixels within ITC, based on estimates of pigments

Study area \& Experimental data

- Experimental site $(200 \times 200 \mathrm{~m})$ located in the North of French Guiana (Paracou)

- Airborne imaging spectroscopy: measured spectral heterogeneity

- $\quad$ LiDAR data (TLS and ALS): accurate definition of 3D structure, including wood and leaves

- $\quad$ ITCs delineation, species inventories and LOPs measured from field spectrometer

- Reconstruction of 3D forest structure from ALS and TLS using AMAPVox

Methods

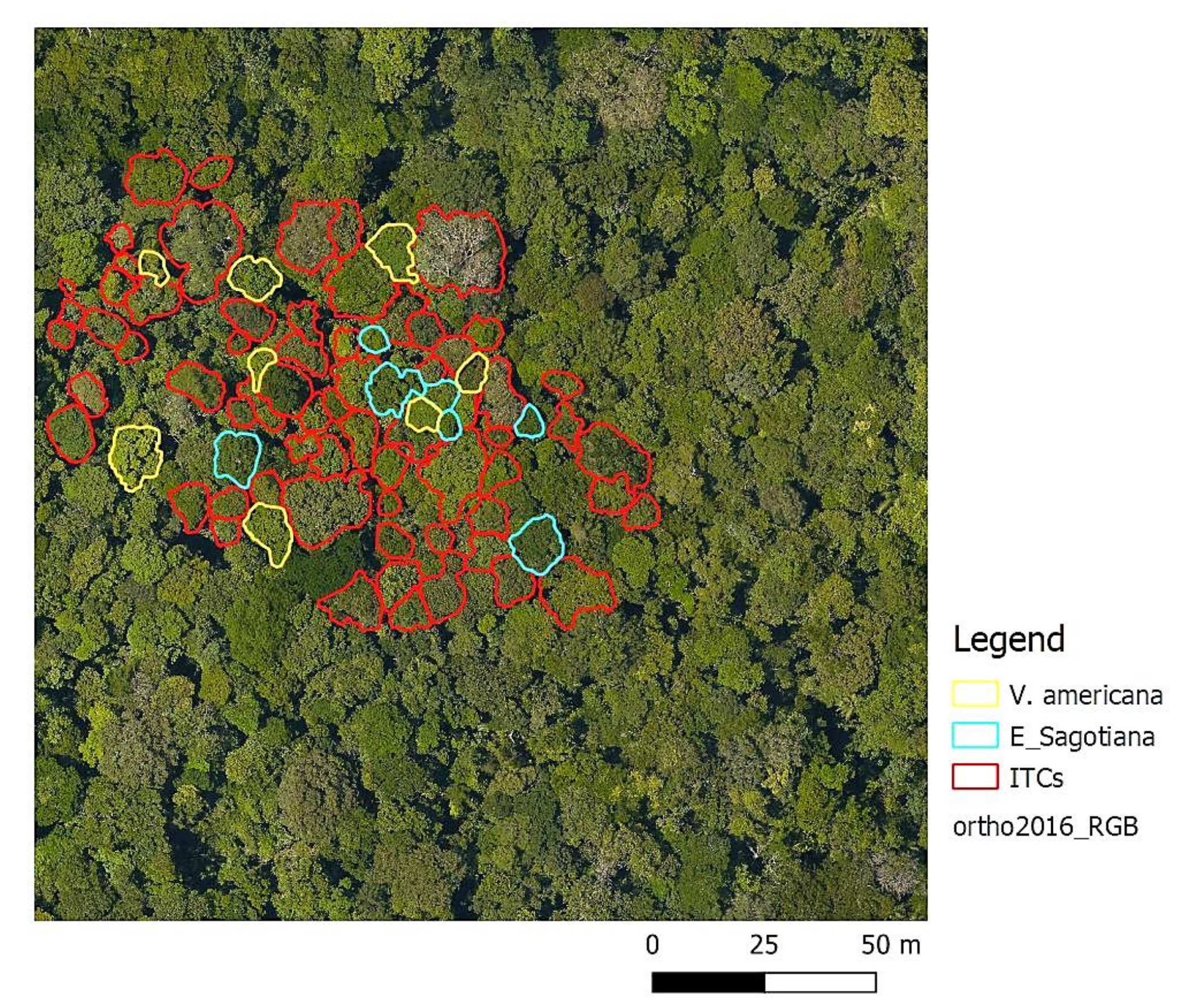

- ITC approach : LOPs measured from an identified ITC with field spectroscopy applied to all pixels of this ITC

- Pixel approach : Estimation of leaf pigments (Chlorophylls - Cab, Carotenoids - Cxc, Anthocyanins) using spectral indices (Gitelson et al. 2006)

- Adjustment of a statistical model between spectral indices and leaf pigment content using DART simulation

- Application of the statistical model on each pixel of experimental airborne imaging spectroscopy

- Compare spectral dissimilarity among and within a selection of species for each approach, using spectral angle

Theoretical relation between leaf chemistry and spectral indices

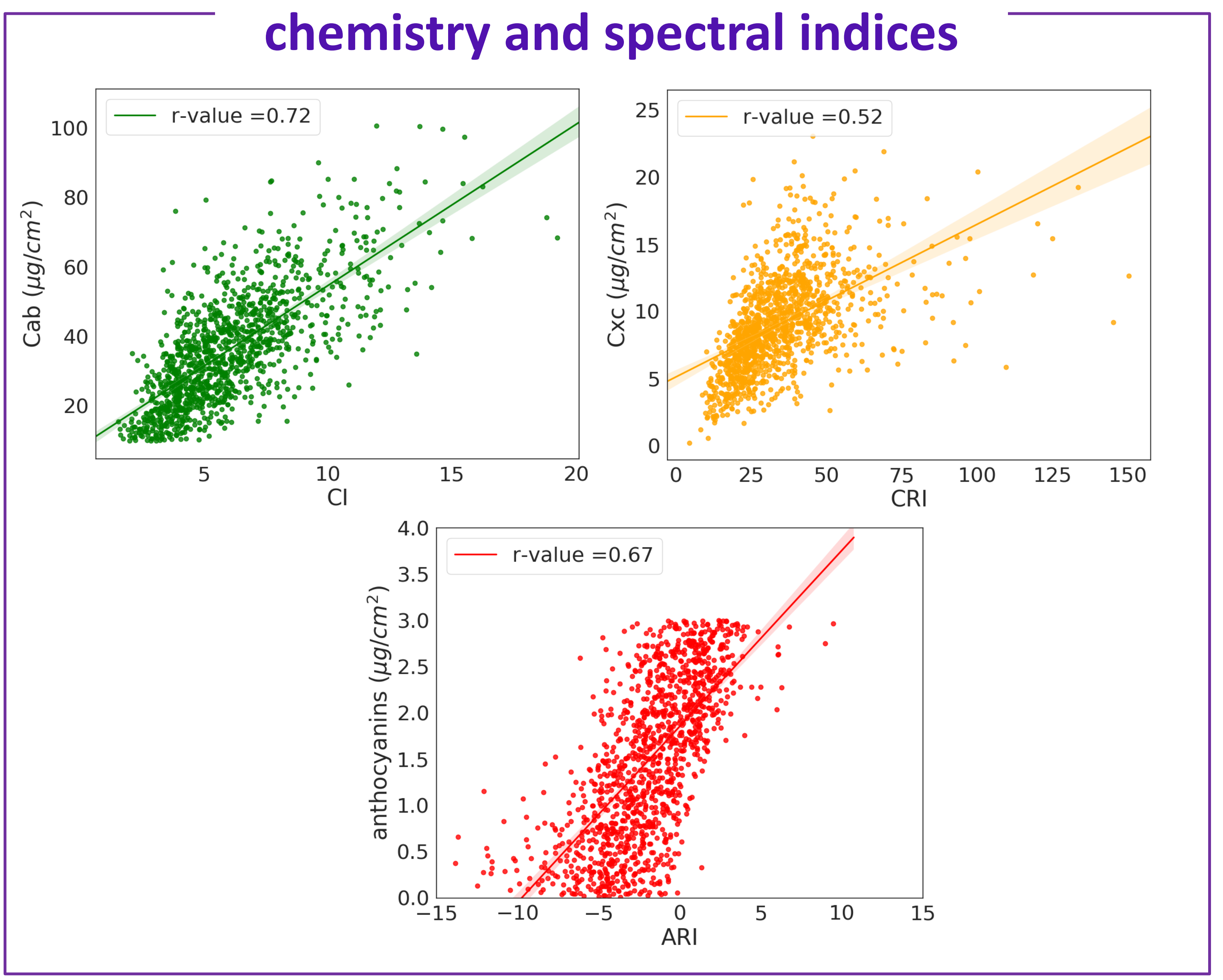

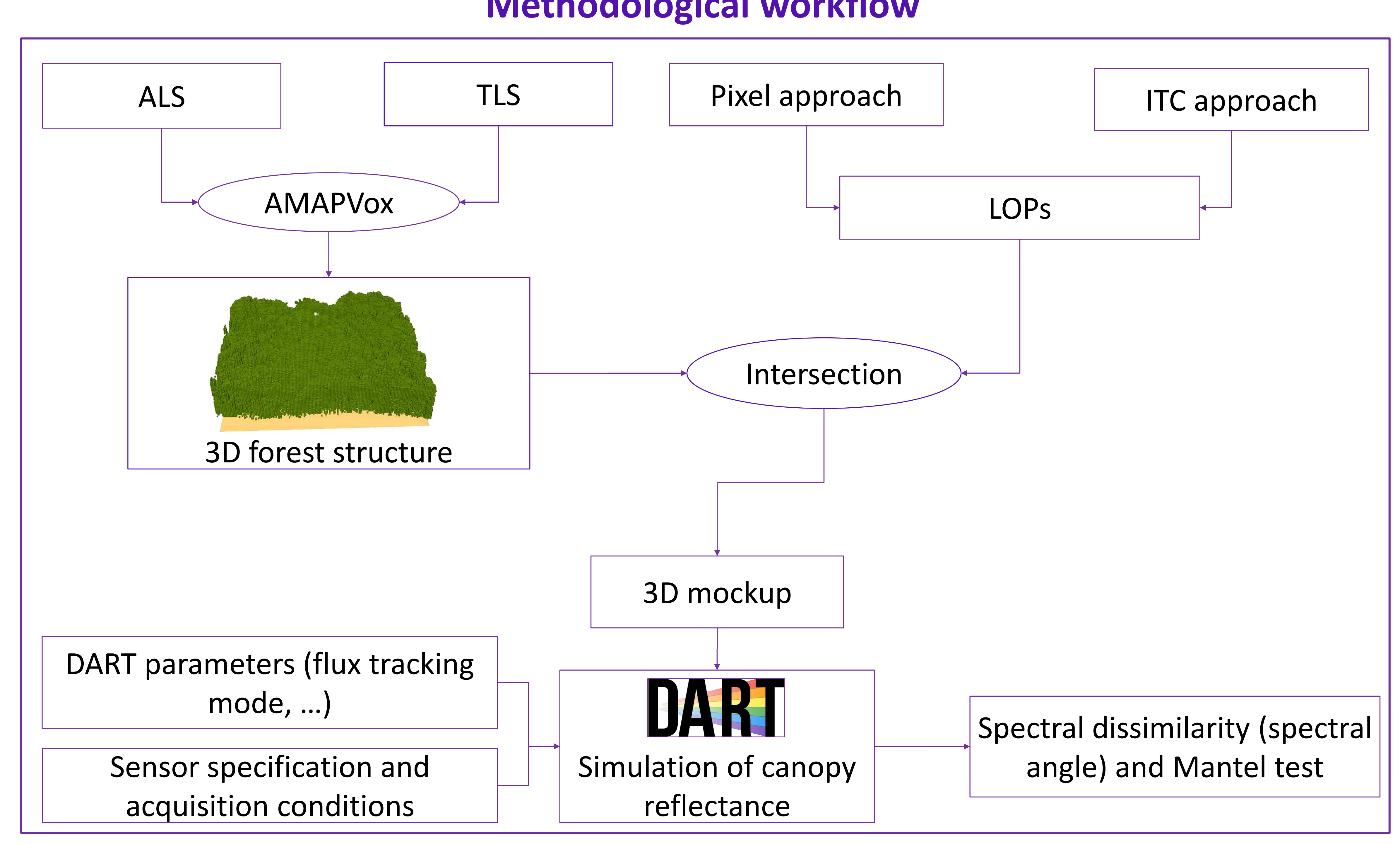

Assessment of spectral dissimilarity
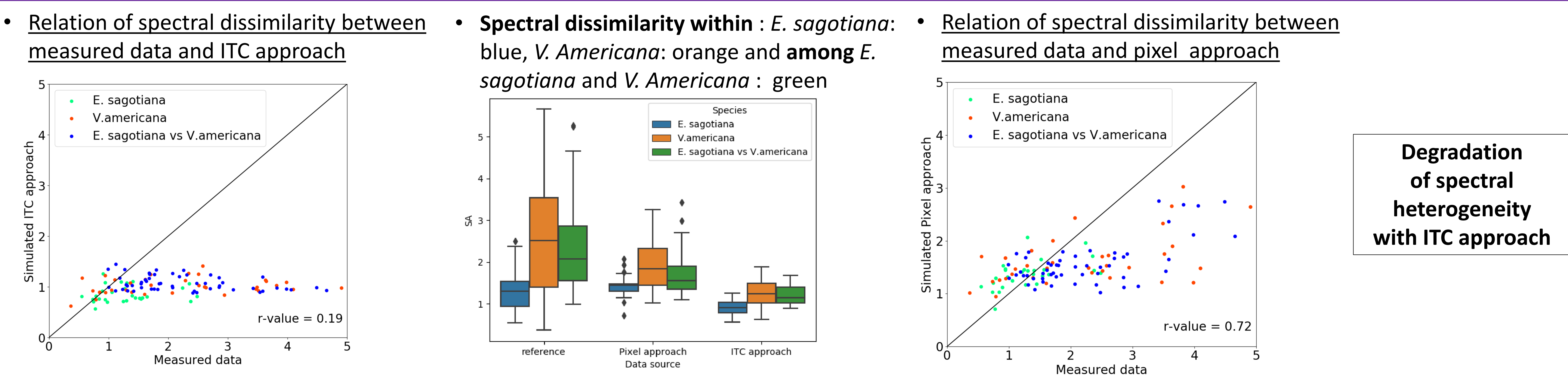

Conclusion \& perspectives

- Two ways of integrating variability in LOPs in 3D RTM have been tested for the simulation of spectral heterogeneity

- Pixel approach outperforms ITC approach : need of many samples (ITCs delineation) for validation

- Need to test other metrics for spectral dissimilarity

\section{References}

- Palmer, M. W., Earls, P. G., Hoagland, B. W., White, P. S., \& Wohlgemuth, T. (2002). Quantitative tools for perfecting species lists. Environmetrics: The official journal of the International Environmetrics Society, 13(2), 121-137.

- Féret, J. B., \& Asner, G. P. (2014). Mapping tropical forest canopy diversity using high-fidelity imaging spectroscopy. Ecological Applications, 24(6), $1289-1296$.

- Gitelson, A. A., Keydan, G. P., \& Merzlyak, M. N. (2006). Three-band model for noninvasive estimation of chlorophyll, carotenoids, and anthocyanin contents in higher plant leaves. Geophysical research letters, 33(11). 